\title{
EVALUASI PEMASANGAN DAN PEMELIHARAAN ALAT PEMADAM API RINGAN DI GRESIK
}

\author{
EVALUATION OF INSTALLATION AND MAINTENANCE OF PORTABLE \\ FIRE EXTINGUISHER IN GRESIK
}

\author{
Rizki Prasetya Wardana \\ PT. Sierad Produce Tbk \\ E-mail: rizkiprasetya995@gmail.com
}

\begin{abstract}
Oil and gas industry is an industry sector that has a high risk of fire. Fire is a potential hazard which can caused material loss, break of the production process and the danger to the human life safety. The aim of this research is to evaluate the installation and maintenance of portable fire extinguisher in PT. Pertamina Lubricants Production Unit Gresik. This research was observational and descriptive research using cross sectional design. The data used are primary data obtained from observations and interviews, and secondary data from documents and other supporting reports. The result showed that management has provided portable fire extinguisher almost every corner of the office building and production areas. The results of the identification of a potential fire hazard in PT. Pertamina Lubricants Production Unit Gresik that there is a potential fire hazard group A (solid materials, except metal), group B (material flammable liquid or gas) and group $C$ (voltage electrical installations). Variables which have been in accordance with Decree of Minister of Labor No.04/ MEN/1980 is the type and condition, within the installation, and the suitability of portable fire extinguisher signs, while variable that does not fit is the mounting height, sign mounting height and maintenance of portable fire extinguisher. The conclusion is PT. Pertamina Lubricants Production Gresik Unit has carried out the installation and maintenance of portable fire extinguishers but some are not in accordance with the regulations.
\end{abstract}

Keywords: fire, installation, maintenance, portable fire extinguisher

\begin{abstract}
ABSTRAK
Industri minyak dan gas merupakan sektor industri yang memiliki risiko tinggi terjadinya kebakaran. Kebakaran merupakan potensi bahaya yang dapat menimbulkan kerugian material, terhentinya proses produksi serta bahaya terhadap keselamatan jiwa manusia. Tujuan dari penelitian ini adalah untuk mengevaluasi pemasangan dan pemeliharaan alat pemadam api ringan (APAR) di PT. Pertamina Lubricants Production Unit Gresik. Penelitian ini merupakan penelitian observasional dan bersifat deskriptif dengan menggunakan desain cross sectional. Data yang digunakan adalah data primer yang diperoleh dari observasi dan wawancara, serta data sekunder dari dokumen dan arsip pendukung lainnya. Hasil penelitian ini menunjukkan bahwa manajemen telah menyediakan APAR hampir di setiap sudut gedung kantor dan area produksi. Hasil identifikasi potensi bahaya kebakaran di PT. Pertamina Lubricants Production Unit Gresik yaitu terdapat potensi bahaya kebakaran golongan A (bahan padat, kecuali logam), golongan B (bahan cair atau gas mudah terbakar) dan golongan C (instalasi listrik bertegangan). Variabel yang telah sesuai dengan Permenaker No.04/MEN/1980 adalah jenis dan kondisi, jarak pemasangan, dan kesesuaian tanda APAR, sedangkan variabel yang tidak sesuai adalah tinggi pemasangan, tinggi pemasangan tanda dan pemeliharaan APAR. Kesimpulan dalam penelitian ini adalah PT. Pertamina Lubricants Production Unit Gresik sudah melakukan pemasangan dan pemeliharaan alat pemadam api ringan namun masih ada beberapa yang belum sesuai dengan peraturan.
\end{abstract}

Kata kunci: APAR, kebakaran, pemasangan, pemeliharaan

\section{PENDAHULUAN}

Pada era globalisasi seperti saat ini, berbagai macam industri mulai menggunakan mesin-mesin dan segala jenis kecanggihan teknologi yang semakin memudahkan manusia terutama dalam proses produksi pada suatu industri. Teknologi yang canggih dapat memberikan kemudahan dalam proses produksi dan menambah jumlah serta ragam bahaya di lingkungan kerja. Semakin canggih alat atau mesin yang digunakan, maka kemungkinan untuk menyebabkan potensi bahaya juga semakin yang tentunya dapat menimbulkan kerugian. 
Menurut Dirjen Minyak dan Gas (2016), industri minyak dan gas mengandung risiko dan potensi bahaya yang sangat besar, salah satunya adalah risiko bahaya kebakaran. Kebakaran merupakan potensi bahaya utama yang dapat menimbulkan kerugian materiil, terhentinya proses produksi hingga menyebabkan jatuhnya korban jiwa. (Hambyah, 2017). Terjadinya kebakaran di tempat kerja dapat menimbulkan kerugian bagi banyak pihak, antara lain bagi perusahaan, pekerja maupun kepentingan Pembangunan Nasional (Kepmenaker RI No: KEP.186/MEN/1999).

Berdasarkan data dari Pusat Laboratorium Fisika Forensik (PUSLABFOR) Mabes Polri pada tahun 2001-2005 terjadi 1121 kasus kebakaran dengan persentase $76,1 \%$ terjadi di tempat kerja dan $23,9 \%$ terjadi bukan di tempat kerja. Selain itu, 20\% kejadian kebakaran berakibat habis total. Di negara berkembang, sebagian besar tenaga kerja terlibat dalam aktivitas berbahaya seperti pertambangan, sektor migas dan industri bahan kimia (ILO, 2013). Pada ketiga sektor industri tersebut memiliki risiko kejadian kebakaran yang tinggi. Tingginya risiko kejadian kebakaran tersebut semakin menjelaskan bahwa kebakaran merupakan potensi bahaya yang perlu ditangani secara serius di tempat kerja.

Semakin berkembangnya teknologi yang digunakan dalam proses produksi serta risiko bahaya yang ditimbulkan, maka sudah seharusnya diiringi pula dengan peningkatan perlindungan terhadap pekerja maupun terhadap seluruh aset perusahaan. Sebagaimana telah diatur dan dijelaskan dalam UU Nomor 1 Tahun 1970 tentang Keselamatan Kerja pasal 3 ayat 1 butir b bahwa ditetapkan syarat keselamatan kerja untuk mencegah, mengurangi dan memadamkan kebakaran. Berdasarkan peraturan tersebut, pemerintah mewajibkan setiap pengurus di tempat kerja untuk mencegah timbulnya kebakaran, mengurangi penyebab terjadinya kebakaran serta memadamkan kebakaran sedini mungkin agar tidak menimbulkan kerugian. Menurut Suma'mur (1989), dengan terjadinya kebakaran yang berlangsung sekejap saja dapat mengakibatkan hilangnya hasil usaha dan upaya yang telah dikerjakan.

Menurut Kepmenaker RI No: KEP.186/ MEN/1999 tentang Penanggulangan Kebakaran di Tempat Kerja dijelaskan bahwa untuk menanggulangi kebakaran di tempat kerja diperlukan sarana pemadam kebakaran yang memadai. Alat Pemadam Api Ringan (APAR) merupakan salah satu sarana pemadam kebakaran yang efisien dan efektif untuk memadamkan api saat awal terjadinya kebakaran. Pada saat terjadi kebakaran, hal yang paling menentukan adalah tindakan awal yang dilakukan karena pada saat itulah kobaran api masih belum terlalu besar dan mudah untuk dikendalikan. Tindakan awal yang dilakukan harus dengan cepat dan tepat agar kobaran api segera padam dan tidak menimbulkan kerugian yang lebih besar.

Penanggulangan kebakaran adalah segala daya upaya untuk mencegah, memberantas dan memadamkan kebakaran. Sebagai langkah awal dalam upaya penanggulangan kebakaran maka dalam sebuah perusahaan perlu diadakan pemasangan dan pemeliharaan Alat Pemadam Api Ringan (APAR) sebagai sarana proteksi kebakaran di tempat kerja. Pemasangan dan pemeliharaan APAR di sektor industri migas harus sangat diperhatikan karena merupakan industri yang memiliki risiko tinggi terjadinya kebakaran. Kesesuaian pemasangan dan pemeliharaan APAR dengan melakukan pemeriksaan dan perawatan secara rutin sangat mendukung suatu upaya penanggulangan kebakaran di tempat kerja yang telah tercantum dalam Permenaker RI No: Per.04/MEN/1980 tentang Syarat-syarat Pemasangan dan Pemeliharaan APAR.

Menurut Permenaker RI No: Per.04/ MEN/1980, APAR merupakan suatu alat yang ringan dan mudah digunakan oleh satu orang yang berfungsi untuk memadamkan api pada awal mula terjadinya kebakaran. Peristiwa kebakaran pada umumnya berawal dari api yang kecil yang tidak dapat dikendalikan dan ditanggulangi sehingga api membesar dan menjadi kobaran api yang menjalar ke benda-benda di sekelilingnya. Setiap kejadian kebakaran tindakan awal penanggulangan sangat menentukan upaya pemadaman api karena pada saat itu api masih relatif kecil dan dapat dengan mudah dikendalikan.

PT. Pertamina Lubricants Production Unit Gresik merupakan Badan Usaha Milik Negara (BUMN) yang baru terbentuk dan diresmikan pada tahun 2013 yang merupakan industri produksi, penimbunan dan pendistribusian pelumas yang melayani kebutuhan pelumas di Indonesia Timur. Pabrik pelumas di Kabupaten Gresik ini memiliki teknologi canggih dan mutakhir yang dapat memproduksi hingga 500.000 kiloliter per tahun (Pertamina Lubricants, 2015). Tingginya proses produksi dengan kecanggihan teknologi dapat meningkatkan risiko terjadinya kecelakaan kerja, khususnya pada sektor industri migas yang dapat meningkatkan risiko kebakaran. Menurut Maruli (2012), penyebab awal terjadinya kebakaran 
sebanyak 41,67\% karena faktor peralatan dan kinerja manusia. Hal ini membuktikan bahwa dengan digunakannya peralatan atau mesin yang canggih ditambah dengan tuntutan kerja akibat proses produksi yang tinggi dapat meningkatkan risiko terjadinya kebakaran di tempat kerja.

PT. Pertamina Lubricants Production Unit Gresik berada satu lokasi dengan PT. Pertamina Pabrik Aspal Gresik. Berdasarkan teori segitiga api (Bird \& Germain, 1985), telah terdapat tiga unsur pemicu api, yaitu minyak mentah (base oil) yang merupakan bahan utama dalam proses pengolahan oli pelumas sebagai bahan mudah terbakar, panas dari sinar matahari, energi listrik maupun uap panas yang ditimbulkan dari proses produksi aspal dan yang terakhir telah tersedianya oksigen $\left(\mathrm{O}_{2}\right)$ yang tersedia di udara bebas (Angela, 2006).

Kasus kebakaran pernah terjadi pada industri sejenis pada 26 September 2015. Kejadian kebakaran tersebut berada di PT. Laguna Industries Nusantara, Tangerang yang merupakan pabrik pengolahan oli bekas. Api membakar habis seluruh bangunan pabrik hingga merembet membakar bangunan lain di sekitarnya. Menurut laporan Polisi Resort Metro Tangerang, dalam kejadian kebakaran tersebut dilaporkan terdapat 2 orang kritis dan kerugian materiil mencapai ratusan juta rupiah. Penyediaan sarana proteksi kebakaran, salah satunya seperti APAR sangatlah dibutuhkan guna memadamkan api pada tahap awal mula sebelum terjadi kobaran api yang lebih besar dan tidak terkendali. Menurut Yervi (2009), APAR efektif digunakan untuk memadamkan kebakaran kecil.

Tujuan dari penelitian ini adalah untuk mengevaluasi pemasangan dan pemeliharaan APAR di PT. Pertamina Lubricants Production Unit Gresik. Evaluasi pemasangan dan pemeliharaan APAR tersebut berpedoman pada Permenaker RI No.Per.04/ MEN/1980 tentang Syarat-syarat Pemasangan dan Pemeliharaan APAR.

\section{METODE}

Penelitian ini merupakan penelitian observasional dan bersifat deskriptif yaitu dengan cara menggambarkan suatu objek tertentu secara sistematis dan faktual dengan melakukan wawancara kepada responden dan melakukan pengamatan menggunakan lembar observasi berupa checklist. Penelitian ini merupakan penelitian cross sectional karena dilakukan dalam periode waktu tertentu (Notoatmodjo, 2012).
Objek dalam penelitian ini adalah sarana proteksi kebakaran berupa Alat Pemadam Api Ringan (APAR) pada PT. Pertamina Lubricants Production Unit Gresik. Teknik pengumpulan data menggunakan panduan wawancara dan lembar checklist. Data yang digunakan dalam penelitian ini adalah data primer yang diperoleh dari observasi dengan menggunakan lembar checklist dan wawancara dengan 3 orang informan yang terdiri dari Supervisor HSSE, safety officer dan petugas HSE lapangan serta data sekunder dari dokumen dan arsip pendukung lainnya. Data yang didapat akan disajikan secara deskriptif dengan melakukan evaluasi dan pengkajian antara hasil temuan di lapangan dengan peraturan yang ada.

Lokasi penelitian berada di PT. Pertamina Lubricants Production Unit Gresik, dengan alamat Jalan Harun Tohir 77, Desa Pulopancikan, Kabupaten Gresik, Jawa Timur. Waktu penelitian dilaksanakan pada April 2017.

Variabel dalam penelitian ini yaitu pemasangan APAR dan pemeliharaan APAR. Pada variabel pemasangan APAR terdiri dari jenis, kapasitas dan kondisi APAR, jarak pemasangan APAR, tinggi pemasangan APAR, tinggi pemberian tanda APAR, dan kesesuaian tanda APAR.

\section{HASIL}

\section{Gambaran Umum PT. Pertamina Lubricants} Production Unit Gresik

PT. Pertamina Lubricants merupakan Badan Usaha Milik Negara (BUMN) anak perusahaan dari PT. Pertamina (Persero) yang didirikan pada 23 September 2013 dan menerima pemisahan (spin-o) Unit Bisnis Pelumas PT. Pertamina (Persero) pada 30 Oktober 2013.

PT. Pertamina Lubricants didirikan sebagai pelaksana amanat Undang-undang Nomor 22 Tahun 2001 tentang Minyak dan Gas. Tujuan pendirian badan usaha ini adalah untuk meningkatkan kekuatan bisnis perseroan di bidang usaha oli pelumas pada masa yang akan datang melalui cakupan bisnis di dalam dan di luar negeri. PT. Pertamina Lubricants bertekat menjadi perusahaan pelumas berkelas dunia dan mencapai posisi Top $20^{\text {th }}$ Word Lubricants Company.

PT. Pertamina (Persero) meresmikan pengoperasian Lube Oil Blending Plant (LOBP) di Unit Produksi Pelumas Pertamina Gresik, Jawa Timur pada 31 Januari 2009. Pembangunan LOBP Gresik dilaksanakan pada tanggal 26 April 2007 
hingga 1 November 2008 dengan nilai proyek mencapai Rp 220 Miliar yang dikerjakan oleh PT. Rekayasa Industri.

PT. Pertamina Lubricants Production Unit Gresik merupakan pabrik produksi oli pelumas paling modern dan ter canggih yang ada di Indonesia. Seluruh proses produksi pada pabrik ini dapat dikontrol melalui program yang bernama lubcell. Kapasitas produksi dari Unit Produksi Gresik ini yaitu mencapai 500.000 kiloliter per tahun, LOBP ini dapat memenuhi sekitar $40 \%$ produksi pelumas pertamina. PT. Pertamina Lubricants Production Unit Gresik bertugas melayani kebutuhan oli pelumas Indonesia Timur, yaitu Sales Region (SR) V yang meliputi Jawa Timur, Bali, Nusa Tenggara, SR VI yang meliputi seluruh wilayah Kalimantan dan SR VII yang meliputi Sulawesi, Maluku dan Papua.

PT. Pertamina Lubricants Production Unit Gresik berdiri di atas lahan seluas $49.610 \mathrm{~m}^{2}$ yang berlokasi di Jalan Harun Tohir 77, Desa Pulopancikan, Kecamatan Gresik, Kabupaten Gresik, Provinsi Jawa Timur. Denah perusahaan PT. Pertamina Lubricants Production Unit Gresik terdiri dari lokasi produksi pelumas dan produksi aspal, kedua proses produksi tersebut tergabung menjadi satu lokasi. Pembagian wilayah kerja pabrik aspal dan pabrik pelumas berbeda karena proses produksi dan struktur organisasi perusahaan juga berbeda.

Visi dari PT. Pertamina Lubricants adalah menjadi perusahaan kelas dunia. Sedangkan misi dari PT. Pertamina Lubricants adalah melaksanakan bisnis solusi pelumasan dan memasarkan pelumas serta produk terkait secara kompetitif di pasar domestik dan luar negeri untuk memperkuat portofolio bisnis guna mengoptimalkan nilai tambah bagi seluruh pemangku kepentingan PT. Pertamina Lubricants memiliki 6 tata nilai yang dimiliki perusahaan, yaitu clean (bersih), competitive (kompetitif), confident (percaya diri), customer focused (fokus pada pelanggan), commercial (komersial) dan capable (berkemampuan).

\section{Kebijakan Penanggulangan Kebakaran PT. Pertamina Lubricants Production Unit Gresik}

PT. Pertamina Production Unit Gresik tidak memiliki kebijakan khusus dan tertulis dalam upaya penanggulangan kebakaran di tempat kerja. Kebijakan tertulis tersebut hanya tersirat dalam kebijakan Quality and HSSE PT. Pertamina Lubricants pada butir ke 6 yang berbunyi,
"Mengutamakan aspek kesehatan, keselamatan kerja dan perlindungan lingkungan".

Tidak adanya kebijakan tertulis mengenai upaya penanggulangan kebakaran tidak membuat manajemen PT. Pertamina Lubricants Production Unit Gresik tidak memperhatikan risiko dan potensi bahaya kebakaran di tempat kerja. Manajemen perusahaan tetap berupaya melakukan upaya penanggulangan kebakaran dengan melakukan penyediaan alat pemadam kebakaran seperti menyediakan APAR di hampir setiap sudut gedung kantor dan area produksi pelumas PT. Pertamina Lubricants Production Unit Gresik. Manajemen juga berupaya melakukan pemeliharaan terhadap seluruh APAR yang telah tersedia agar APAR selalu dalam kondisi baik dan siap digunakan saat terjadi keadaan darurat kebakaran di tempat kerja. Manajemen juga menyediakan sarana evakuasi kebakaran bagi seluruh pekerja dan tamu perusahaan apabila sewaktu-waktu terjadi keadaan darurat kebakaran. Manajemen juga menyediakan nomor telepon penting yang dapat dihubungi dengan segera pada saat terjadi keadaan darurat kebakaran, seperti nomor telepon Dinas Pemadam Kebakaran Kabupaten Gresik, Rumah Sakit terdekat dan nomor telepon penting lainnya.

PT. Pertamina Lubricants Production Unit Gresik melalui fungsi HSSE memiliki beberapa program kerja dalam upaya penanggulangan kebakaran di tempat kerja. Beberapa program kerja tersebut antara lain pelatihan penggunaan APAR, pelatihan pemadaman api menggunakan APAR dan alat pemadam kebakaran lainnya, safety talk mengenai segitiga api dan simulasi keadaan darurat kebakaran. Semua program dalam upaya penanggulangan kebakaran tersebut belum dilaksanakan secara rutin dan berkala.

Manajemen PT. Pertamina Lubricants Production Unit Gresik telah membentuk tim khusus dalam upaya penanggulangan kebakaran di tempat kerja. Tim khusus penanggulangan kebakaran di tempat kerja tersebut diberi nama Organisasi Keadaan Darurat (OKD). Selain itu, PT. Pertamina Lubricants Production Unit Gresik juga telah memiliki buku rencana penanggulangan keadaan darurat yang diberi nama Buku Panduan K3LL yang menjelaskan tentang segala upaya pengendalian segala bentuk energi, pencegahan kecelakaan, kebocoran, kebakaran dan prosedur keadaan darurat yang harus dilaksanakan tim khusus OKD. 


\section{Identifikasi Potensi Bahaya Kebakaran PT. Pertamina Lubricants Production Unit Gresik}

Pada gedung kantor PT. Pertamina Lubricants Production Unit Gresik memiliki potensi bahaya kebakaran golongan A dan C. Gedung kantor memiliki potensi bahaya kebakaran, yaitu bahan-bahan padat seperti kayu, kertas, plastik, kardus serta bahaya kebakaran yang diakibatkan oleh aliran listrik yang digunakan dalam pengoperasian alat kerja, penerangan dan pendingin ruangan.

Pada area produksi pelumas PT. Pertamina Lubricants Production Unit Gresik memiliki potensi bahaya kebakaran golongan A, B dan C. Area produksi pelumas memiliki potensi bahaya kebakaran, yaitu bahan-bahan padat seperti pallet forklift, botol lithos, kardus packaging, bahan cair mudah terbakar berupa pelumas dan zat additive lainnya, aliran listrik bertegangan tinggi yang digunakan oleh mesin produksi, compressor dan untuk penerangan ruangan.

Pada area gudang material dan finish product memiliki potensi bahaya kebakaran golongan A, $\mathrm{B}$ dan C. Area gudang memiliki potensi bahaya kebakaran yaitu bahan padat seperti botol lithos, kardus packaging, kertas dan sticker product untuk proses produksi, plastik, karton, bahan cair mudah terbakar berupa pelumas yang sudah dikemas dalam botol lithos dan drum, serta aliran listrik yang digunakan untuk penerangan. Penumpukan barang di gudang tersebut hingga ketinggian 5-7 meter.

Berdasarkan hasil identifikasi tersebut, PT. Pertamina Lubricants Production Unit Gresik memiliki potensi bahaya kebakaran yaitu golongan A (kebakaran bahan padat, kecuali logam), golongan B (kebakaran bahan cair dan gas) dan golongan C (kebakaran instalasi listrik bertegangan). PT. Pertamina Lubricants Production Unit Gresik dapat diklasifikasikan dalam risiko bahaya kebakaran berat. Menurut Kepmenaker RI No: KEP.186/ MEN/1999 tentang Penanggulangan Kebakaran di Tempat Kerja bahwa klasifikasi tingkat risiko bahaya kebakaran berat adalah tempat kerja yang mempunyai jumlah dan kemudahan terbakar tinggi, menyimpan bahan cair, serat atau bahan lainnya dan apabila terjadi kebakaran apinya cepat membesar dengan melepaskan panas tinggi, sehingga menjalarnya api cepat.
Tabel 1. APAR di PT. Pertamina Lubricants Production Unit Gresik Tahun 2017

\begin{tabular}{lcr}
\hline Merk & Jenis/Ukuran & Jumlah \\
\hline APAR Gunnebo & $\mathrm{DCP} / 12 \mathrm{~kg}$ & $25 \mathrm{Buah}$ \\
APAR Red Guard & $\mathrm{DCP} / 9 \mathrm{~kg}$ & $18 \mathrm{Buah}$ \\
APAR Ansul & $\mathrm{DCP} / 9 \mathrm{~kg}$ & $14 \mathrm{Buah}$ \\
APAR Gloria & $\mathrm{DCP} / 6 \mathrm{~kg}$ & $2 \mathrm{Buah}$ \\
APAR Alpindo & $\mathrm{DCP} / 6 \mathrm{~kg}$ & $12 \mathrm{Buah}$ \\
APAR Ansul & $\mathrm{DCP} / 1,5 \mathrm{~kg}$ & $6 \mathrm{Buah}$ \\
APAR Alpindo & $\mathrm{DCP} / 1,5 \mathrm{~kg}$ & $5 \mathrm{Buah}$ \\
APAR Alpindo & $\mathrm{CO}_{2} / 4,5 \mathrm{~kg}$ & $31 \mathrm{Buah}$ \\
Ondioxide & $\mathrm{CO}_{2} / 4,5 \mathrm{~kg}$ & $1 \mathrm{Buah}$ \\
\hline Total APAR & & $114 \mathrm{Buah}$ \\
\hline
\end{tabular}

Sumber: Data K3LL PUG Tahun 2014

\section{Pemasangan APAR}

\section{Jenis, Kapasitas dan Kondisi APAR}

PT. Pertamina Lubricants Production Unit Gresik telah melakukan pemasangan APAR yang diletakkan di seluruh lokasi gedung kantor, area produksi dan gudang. APAR yang disediakan oleh manajemen terdiri dari 2 jenis, yaitu APAR berjenis gas $\mathrm{CO}_{2}$ dan APAR berjenis powder (Dry Chemical Powder/DCP).

Wawancara dan observasi terkait APAR di PT. Pertamina Lubricants Production Unit Gresik menjelaskan bahwa terdapat 29 buah APAR dengan kondisi tidak baik dan rusak yang telah ditempatkan di Posko K3LL PT. Pertamina Lubricants Production Unit Gresik. Sebanyak 29 buah APAR tersebut memiliki kondisi yang tidak baik dikarenakan slang/hose dalam kondisi retak dan rusak, tidak memiliki tekanan (tekanan kosong) dan memiliki cacat pada tabung APAR, seperti warna sudah pudar dan telah muncul karat. Jumlah keseluruhan APAR dengan kondisi baik dan siap digunakan berjumlah 85 buah.

Pemilihan dan penempatan jenis APAR telah sesuai dengan golongan risiko bahaya kebakaran yang ada di PT. Pertamina Lubricants Production Unit Gresik. Manajemen telah menentukan APAR yang digunakan dalam upaya penanggulangan kebakaran adalah APAR berjenis powder (Dry Chemical powder/DCP) yang efektif dalam 
memadamkan kebakaran baik kebakaran golongan $\mathrm{A}, \mathrm{B}$ maupun $\mathrm{C}$ dan APAR berjenis $\mathrm{CO}_{2}$ yang efektif digunakan untuk memadamkan kebakaran golongan $B$ yaitu olahan minyak maupun oli pelumas yang sudah jadi. APAR berjenis $\mathrm{CO}_{2}$ banyak diletakkan di area produksi sedangkan APAR berjenis DCP diletakkan di seluruh sudut gedung kantor maupun area produksi PT. Pertamina Lubricants Production Unit Gresik.

Terdapat 3 cara peletakan APAR di PT. Pertamina Lubricants Production Unit Gresik, yaitu dengan cara diletakkan menggantung, diletakkan di lemari (box) dan diletakkan di lantai dengan sebuah keranjang. Lemari tempat meletakkan APAR dalam kondisi terkunci dengan terdapat kunci pembuka yang menggantung terlindung dalam sebuah kaca aman (safety glass). Saat kondisi darurat kebakaran, pekerja dapat memecahkan kaca aman tersebut untuk mengambil kunci pembuka yang digantung dan membuka lemari APAR untuk selanjutnya melakukan pemadaman api. Pada area laboratorium, APAR diletakkan dalam sebuah keranjang yang ditempatkan di lantai. Pada lemari dan keranjang tersebut diletakkan dua jenis APAR yaitu APAR jenis DCP dan $\mathrm{CO}_{2}$.

APAR yang terpasang di PT. Pertamina Lubricants Production Unit Gresik seluruhnya berwarna merah dan diletakkan pada posisi yang mudah dilihat dengan jelas, mudah dicapai dan mudah diambil. Berdasarkan pengukuran suhu ruangan oleh petugas HSE lapangan pada beberapa lokasi APAR terpasang, didapatkan hasil pengukuran berkisar antara $33^{\circ} \mathrm{C}$ hingga menyentuh suhu $45^{\circ} \mathrm{C}$ pada siang hari yang terik. APAR yang terpasang juga telah tercantum petunjuk cara pemakaian APAR yang dapat dibaca dengan cukup jelas di bagian tabung APAR. APAR yang tidak mencantumkan petunjuk cara pemakaian, maka oleh pihak manajemen dipasang pamflet, pigura atau papan petunjuk cara pemakaian di sekitar APAR tersebut terpasang yang dapat dibaca oleh pekerja dengan jelas.

\section{Jarak Pemasangan APAR}

Hasil observasi menunjukkan PT. Pertamina Lubricants Production Unit Gresik memasang atau meletakkan APAR yang satu dengan lainnya dengan jarak 10-15 meter. Pada beberapa area seperti pada area produksi, gudang, gedung kantor, tangki timbun, area utility dan Tempat Penyimpanan Sementara (TPS) limbah B3 maupun non-B3 peletakan APAR atau kelompok APAR yang satu dengan lainnya dengan jarak rata-rata 10 meter.

Sepanjang jalan utama pada area produksi (plant), manajemen PT. Pertamina Lubricants Production Unit Gresik meletakkan beberapa Alat Pemadam Api Beroda (APAB) dengan berat 150 dan $350 \mathrm{lbs}$ sebagai upaya penanggulangan kebakaran. Manajemen juga telah memasang hydrant lapangan di sepanjang jalan utama yang dipasang di seluruh bagian pada jalan utama. Hydrant lapangan dipasang di pinggir jalan utama sebagai upaya penanggulangan kebakaran apabila api sudah mulai membesar dan telah terjadi keadaan darurat kebakaran.

\section{Tinggi Pemasangan APAR}

Berdasarkan hasil observasi pada beberapa APAR di PT. Pertamina Lubricants Production Unit Gresik, pemasangan APAR di area gudang material, area gudang finish product, area filling lithos, area filling drum, area printing and dosing manual preparation, area Viscosity Modifier, area Tempat Penyimpanan Sementara (TPS) limbah B3 dan kantin dipasang menggantung pada dinding dengan bagian paling atas (puncaknya) berada pada ketinggian antara 1,2 hingga 1,3 meter dari permukaan lantai.

Pemasangan APAR pada gedung kantor, area pengangkutan drum oleh forklift, area blending dan area TPS limbah padat non-B3 dipasang menggantung pada dinding dengan bagian paling atas (puncaknya) berada pada ketinggian antara 1,4 hingga 1,5 meter dari permukaan lantai

Pada area laboratorium, APAR diletakkan pada sebuah keranjang yang ditempatkan di lantai. Pada keranjang tersebut tersedia dua jenis APAR yaitu APAR DCP dan $\mathrm{CO}_{2}$. Tinggi antara dasar kelompok APAR tersebut adalah $25 \mathrm{~cm}$ dari permukaan lantai.

Terdapat juga kelompok APAR yang diletakkan dalam sebuah lemari (box). Lemari tersebut juga didalamnya terdapat 2 jenis APAR yaitu APAR DCP dan $\mathrm{CO}_{2}$. Bagian paling atas lemari tersebut berada pada ketinggian 2,5 meter dari permukaan lantai, sedangkan bagian paling atas dari kelompok APAR yang diletakkan di dalam lemari tersebut bagian paling atas (puncaknya) berada pada ketinggian 1,8 meter dari permukaan lantai.

\section{Tinggi Pemberian Tanda APAR}

Berdasarkan hasil observasi pada beberapa APAR di PT. Pertamina Lubricants Production Unit 
Gresik, pemberian tanda APAR pada area gudang material, area gudang finish product, area filling drum, area printing and dosing manual preparation, area Viscosity Modifier, TPS limbah B3 dan kantin dipasang dengan ketinggian 125 hingga $135 \mathrm{~cm}$ dari dasar permukaan lantai tepat di atas APAR yang bersangkutan.

Tinggi pemberian tanda APAR pada gedung kantor, area blending dan area filling lithos dipasang dengan ketinggian mencapai 2 meter dari dasar permukaan lantai tepat di atas APAR yang bersangkutan. Pada area laboratorium, pemberian tanda APAR dipasang dengan ketinggian $60 \mathrm{~cm}$ dari dasar permukaan lantai tepat di atas kelompok APAR yang bersangkutan.

Terdapat APAR yang terpasang dengan tidak diberi tanda APAR. APAR yang tidak diberi tanda pemasangan tersebut berada pada area TPS limbah padat non-B3, area pengangkutan drum oleh forklift dan pada area printing and dosing manual preparation terdapat 1 buah APAR yang terpasang dengan tidak diberi tanda APAR. Kelompok APAR yang diletakkan dalam sebuah lemari seluruhnya juga tidak diberi tanda APAR oleh manajemen PT. Pertamina Lubricants Production Unit Gresik.

\section{Kesesuaian Tanda APAR}

Berdasarkan hasil observasi pada beberapa APAR di PT. Pertamina Lubricants Production Unit Gresik, terdapat tiga jenis tanda APAR yang terpasang di dinding. Jenis tanda APAR yang pertama merupakan tanda APAR yang dipasang di dinding berbentuk segitiga sama sisi terbalik berwarna dasar merah dengan ukuran sisi $35 \mathrm{~cm}$, tulisan ALAT PEMADAM API berwarna putih dengan tinggi huruf $3 \mathrm{~cm}$ dan tanda panah berwarna putih dengan tinggi $7,5 \mathrm{~cm}$. Jenis tanda APAR tersebut terdapat pada area filling lithos, area filling drum, area viscosity modifier, dan area printing and dosing manual preparation.

Jenis tanda APAR yang kedua merupakan tanda APAR yang dipasang di dinding berbentuk segitiga sama sisi terbalik berwarna dasar merah dengan ukuran sisi $17 \mathrm{~cm}$, tulisan ALAT PEMADAM API berwarna putih dengan tinggi huruf $2,5 \mathrm{~cm}$ dan tanda panah berwarna putih dengan tinggi $3,5 \mathrm{~cm}$. Jenis tanda APAR tersebut terdapat pada gedung kantor, TPS limbah B3, area gudang material, area gudang finish product dan kantin.

Jenis tanda APAR yang ketiga merupakan tanda APAR yang dipasang di dinding berbentuk persegi berwarna dasar merah dengan ukuran $40 \mathrm{~cm}$ $\times 20 \mathrm{~cm}$, tulisan ALAT PEMADAM API berwarna putih dengan tinggi huruf $6 \mathrm{~cm}$ dan tanda panah berwarna putih dengan tinggi $15 \mathrm{~cm}$. Jenis tanda APAR tersebut terdapat pada area laboratorium PT. Pertamina Lubricants Production Unit Gresik.

\section{Pemeliharaan APAR}

Berdasarkan hasil wawancara, petugas Health Safety Environment (HSE) lapangan telah melakukan inspeksi/ pemeriksaan pada setiap APAR yang terpasang pada area gedung kantor maupun area produksi PT. Pertamina Lubricants Production Unit Gresik. Pemeriksaan pada APAR tersebut dilakukan secara berkala setiap satu bulan sekali.

Berdasarkan hasil observasi, pada setiap APAR yang terpasang telah terdapat kartu tanda pemeriksaan dan kartu tanda pemeliharaan (service). Kartu tersebut berisi tanggal pemeriksaan, hasil pemeriksaan/pemeliharaan, petugas HSE lapangan yang telah melakukan pemeriksaan pada APAR yang bersangkutan dan paraf petugas HSE Lapangan yang bersangkutan. Berdasarkan hasil wawancara, diketahui bahwa perbedaan antara pemeriksaan dan pemeliharaan yang tertera pada kartu tanda APAR tersebut adalah pemeriksaan merupakan proses pengecekan pada APAR dengan tujuan untuk mengetahui jika terdapat APAR yang mengalami kerusakan maupun kecacatan, sedangkan pemeliharaan merupakan tindak lanjut untuk melakukan penanganan dan perbaikan terhadap APAR yang mengalami kerusakan maupun kecacatan tersebut.

Berdasarkan hasil wawancara, pemeriksaan APAR yang dilakukan oleh petugas HSE Lapangan sejauh ini hanya pemeriksaan kondisi umum APAR secara visual. Pemeriksaan tersebut meliputi pemeriksaan tekanan APAR, pemeriksaan pada segel pengaman (lock pin), pemeriksaan pada corong penyemprot (nozzle), pemeriksaan pada selang (hose), pemeriksaan pada katup (valve), pemeriksaan kondisi tabung (cylinder) dan pemeriksaan kebersihan APAR. Hasil pemeriksaan APAR tersebut selanjutnya ditulis pada kartu tanda pemeriksaan dengan menuliskan kondisi APAR tersebut. Hasil pemeriksaan APAR jika dinyatakan rusak atau cacat maka petugas HSE lapangan segera melakukan perbaikan maupun penggantian dengan APAR yang baru, selanjutnya ditulis dalam kartu tanda pemeliharaan yang menandakan bahwa telah 
dilakukan penanganan perbaikan terhadap APAR yang bersangkutan.

\section{PEMBAHASAN}

\section{Kebijakan Penanggulangan Kebakaran PT. Pertamina Lubricants Production Unit Gresik}

PT. Pertamina Lubricants Production Unit Gresik merupakan perusahaan yang berpotensi timbulnya suatu kejadian kebakaran. Teori segitiga api (Bird \& Germain, 1985) menyatakan bahwa terdapat tiga unsur pemicu api, yaitu minyak mentah (base oil) yang merupakan bahan utama dalam proses pengolahan oli pelumas sebagai bahan mudah terbakar, panas dari sinar matahari, energi listrik maupun uap panas yang ditimbulkan dari proses produksi aspal PT. Pertamina Pabrik Aspal Gresik yang berada satu lokasi dengan PT. Pertamina Lubricants Production Unit Gresik dan telah tersedianya oksigen $\left(\mathrm{O}_{2}\right)$ pada udara bebas.

Agar tidak terjadi kejadian kebakaran yang dapat mengancam keselamatan pekerja dan tamu serta menimbulkan kerugian materiil dan asset berharga perusahaan, maka perlu dibuat suatu kebijakan sebagai upaya penanggulangan kebakaran bila sewaktu-waktu terjadi keadaan darurat kebakaran. Tujuan dibuatnya kebijakan penanggulangan kebakaran ini agar dapat meminimalisir kerugian dan korban jiwa yang diakibatkan oleh suatu kejadian kebakaran.

Sesuai dengan UU No.1 Tahun 1970 tentang Keselamatan Kerja pasal 3 ayat 1 butir b dan Kepmenaker RI No: KEP.186/MEN/1999 tentang Penanggulangan Kebakaran di Tempat Kerja pasal 2 ayat 1 yang mewajibkan pengurus atau pengusaha untuk melakukan upaya pencegahan, mengurangi potensi bahaya kebakaran dan melakukan upaya pemadaman kebakaran yang terjadi di tempat kerja. PT. Pertamina Lubricants Production Unit Gresik telah berupaya menjalankan peraturan tersebut dengan menyediakan alat pemadam kebakaran, sistem proteksi kebakaran, sarana evakuasi, pelatihan penanggulangan kebakaran, pembentukan tim khusus penanggulangan kebakaran, penyediaan nomor telepon penting ketika terjadi keadaan darurat kebakaran serta telah memiliki buku rencana penanggulangan keadaan darurat.

PT. Pertamina Lubricants Production Unit Gresik tidak memiliki kebijakan khusus dan tertulis mengenai upaya penanggulangan kebakaran di tempat kerja. Pihak manajemen tetap menyadari akan bahaya kebakaran yang kapan pun dapat terjadi sehingga dapat menimbulkan korban jiwa dan kerugian materiil. Pihak manajemen tetap berupaya mengutamakan aspek kesehatan, keselamatan kerja dan lindung lingkungan yang sesuai dengan Kebijakan Quality dan HSSE PT. Pertamina Lubricants pada butir ke 6. Menurut Dirjen Migas (2015), segala usaha produksi dan pengolahan minyak dan gas harus sesuai dengan standar operasional yang tinggi serta mengedepankan aspek K3L.

Berdasarkan Kepmenaker RI No: KEP.186/ MEN/1999 tentang Penanggulangan Kebakaran di Tempat Kerja pasal 2 ayat 2 dijelaskan bahwa kewajiban melakukan upaya penanggulangan kebakaran di tempat kerja juga meliputi menyelenggarakan pelatihan penanggulangan kebakaran secara berkala. Hasil wawancara menunjukkan bahwa pelatihan penggunaan APAR dan pelatihan pemadaman api di PT. Pertamina Lubricants Production Unit Gresik belum dilaksanakan secara berkala. Hal ini menunjukkan belum sesuainya kebijakan pelatihan penanggulangan kebakaran yang dilaksanakan oleh pihak manajemen dengan peraturan tersebut.

\section{Identifikasi Potensi Bahaya Kebakaran PT. Pertamina Lubricants Production Unit Gresik}

Menurut Permenaker RI No: PER.04/MEN/1980 tentang Syarat-syarat Pemasangan dan Pemeliharaan APAR pasal 2 ayat 1 menjelaskan bahwa kebakaran bahan padat kecuali logam merupakan kebakaran golongan A, kebakaran bahan cair atau gas yang mudah terbakar merupakan kebakaran golongan B, kebakaran instalasi listrik bertegangan merupakan kebakaran golongan $\mathrm{C}$ dan kebakaran logam merupakan kebakaran golongan D. Berdasarkan hasil identifikasi potensi bahaya kebakaran, PT. Pertamina Lubricants Production Unit Gresik memiliki potensi bahaya kebakaran dengan golongan A, golongan $\mathrm{B}$ dan golongan $\mathrm{C}$.

PT. Pertamina Lubricants Production Unit Gresik dapat diklasifikasikan dalam risiko bahaya kebakaran berat. Menurut Kepmenaker RI No: KEP.186/MEN/1999 tentang Penanggulangan Kebakaran di Tempat Kerja bahwa tingkat risiko bahaya kebakaran berat adalah tempat kerja yang mempunyai jumlah dan kemudahan terbakar tinggi, menyimpan bahan cair, serat atau bahan lainnya dan apabila terjadi kebakaran apinya cepat membesar dengan melepaskan panas tinggi, sehingga menjalarnya api cepat. PT. Pertamina Lubricants Production Unit Gresik sesuai dengan penjelasan 
tersebut bahwa tempat kerja ini memiliki jumlah dan kemudahan terbakar tinggi yang dibuktikan dengan begitu luasnya area pabrik ini ditambah lagi sangat mudah terjadi kebakaran karena melakukan penimbunan bahan cair yang mudah terbakar seperti minyak mentah dan produk jadi oli pelumas yang belum didistribusikan.

\section{Pemasangan APAR}

\section{Jenis, Kapasitas dan Kondisi APAR}

PT. Pertamina Lubricants Production Unit Gresik telah melakukan pemasangan APAR yang diletakkan di seluruh lokasi gedung kantor, area produksi dan area gudang. APAR yang disediakan oleh manajemen terdiri dari dua jenis, yaitu APAR berjenis $\mathrm{CO}_{2}$ dan APAR berjenis powder (Dry Chemical Powder). Menurut Permenaker RI No: PER.04/MEN/1980 tentang Syarat-syarat Pemasangan dan Pemeliharaan APAR dijelaskan bahwa APAR berjenis $\mathrm{CO}_{2}$ dapat dipakai ketika terjadi kebakaran golongan $\mathrm{A}$, baik digunakan untuk memadamkan kebakaran golongan B dan sangat baik digunakan untuk memadamkan kebakaran golongan C. Sedangkan APAR berjenis powder (Dry Chemical Powder) sangat efektif digunakan untuk memadamkan kebakaran golongan A, B maupun C. Kebijakan manajemen telah sesuai dengan peraturan tersebut dengan memilih dua jenis APAR yang efektif digunakan untuk memadamkan kebakaran golongan $\mathrm{A}, \mathrm{B}$ dan $\mathrm{C}$ sesuai dengan risiko bahaya kebakaran yang dapat terjadi di PT. Pertamina Lubricants Production Unit Gresik. Selain itu, hal ini juga telah sesuai dengan peraturan yang menjelaskan tentang pemasangan dan penempatan APAR harus sesuai dengan jenis dan penggolongan kebakaran yang tercantum pada pasal 4 ayat 4 .

Berdasarkan hasil wawancara dan observasi terkait APAR, terdapat 29 buah APAR dengan kondisi tidak baik dan rusak/cacat. APAR dengan kondisi tidak baik dan rusak/cacat tersebut telah diletakkan terpisah ditempatkan di posko K3LL. Hal ini telah sesuai dengan Permenaker RI No: PER.04/ MEN/1980 pasal 5 yang melarang pemasangan dan penggunaan APAR yang didapati telah berlubang, rusak atau cacat karena karat.

Pada Permenaker RI No.04/MEN/1980 pasal 6 dijelaskan bahwa setiap APAR harus dipasang menggantung pada dinding atau ditempatkan dalam sebuah lemari (box), dapat dikunci dengan syarat bagian depannya harus diberi kaca aman (safety glass). Terdapat 2 cara peletakan APAR di PT. Pertamina Lubricants Production Unit Gresik yang telah sesuai dengan peraturan tersebut, yaitu dengan cara diletakkan menggantung dan ditempatkan dalam lemari (box) dikunci dengan disediakan kunci pembuka lemari tersebut dalam sebuah kaca aman (safety glass).

APAR yang terpasang di PT. Pertamina Lubricants Production Unit Gresik seluruhnya berwarna merah dan diletakkan posisi yang mudah dilihat dengan jelas, mudah dicapai dan diambil serta telah dilengkapi dengan tanda pemasangan APAR, hal ini telah sesuai dengan Permenaker RI No.04/MEN/1980 pasal 4. Berdasarkan pengukuran suhu ruangan oleh petugas HSE lapangan pada beberapa lokasi APAR terpasang, didapatkan hasil pengukuran berkisar antara $33^{\circ} \mathrm{C}$ hingga menyentuh suhu $45^{\circ} \mathrm{C}$ pada siang hari yang terik, hal ini telah sesuai Permenaker RI No.04/MEN/1980 pasal 9 yang menjelaskan bahwa APAR tidak diperbolehkan diletakkan pada tempat yang suhu ruangannya melebihi $49^{\circ} \mathrm{C}$ atau turun hingga minus $44^{\circ} \mathrm{C}$. Selain itu, sesuai dengan Permenaker RI No.04/ MEN/1980 pasal 14 yang menjelaskan bahwa harus mencantumkan petunjuk cara pemakaian APAR dengan jelas, APAR yang terpasang di PT. Pertamina Lubricants Production Unit Gresik telah tercantum petunjuk cara pemakaian APAR. Adapun APAR yang tidak mencantumkan petunjuk cara pemakaian, maka oleh pihak manajemen telah dipasang pamflet atau papan petunjuk pemakaian di samping atau di sekitar APAR yang bersangkutan.

\section{Jarak Pemasangan APAR}

Berdasarkan hasil observasi, PT. Pertamina Lubricants Production Unit Gresik memasang dan meletakkan APAR atau kelompok APAR yang satu dengan lainnya dengan jarak 10-15 meter. Pada beberapa area seperti pada area produksi, gudang, gedung kantor, tangki timbun, area utility dan TPS (Tempat Penyimpanan Sementara) limbah B3 maupun non-B3 peletakan APAR atau kelompok APAR yang satu dengan lainnya dengan jarak rata-rata 10 meter. Hal ini telah sesuai dengan Permenaker RI No.04/MEN/1980 pasal 4 ayat 5 yang menjelaskan bahwa pemasangan APAR atau kelompok APAR yang satu dengan lainnya tidak melebihi 15 meter, kecuali ditetapkan lain oleh pegawai pengawas atau ahli keselamatan kerja. 


\section{Tinggi Pemasangan APAR}

Berdasarkan hasil observasi, pemasangan APAR di PT. Pertamina Lubricants Production Unit Gresik terdiri dari 4 varian ketinggian. Pada varian pertama dipasang menggantung pada dinding dengan bagian paling atas (puncaknya) berada pada ketinggian 1,2 hingga 1,3 meter dari permukaan lantai. Pada varian kedua, dipasang menggantung pada dinding dengan bagian paling atas (puncaknya) berada pada ketinggian 1,4 hingga 1,5 meter dari permukaan lantai. Pada varian ketiga, diletakkan dalam sebuah lemari (box) dengan bagian paling atas lemari tersebut berada pada ketinggian 2,5 meter dari permukaan lantai, sedangkan bagian paling atas dari kelompok APAR yang diletakkan di dalam lemari tersebut berada pada ketinggian 1,8 meter dari permukaan lantai. Ketiga varian ketinggian tersebut tidak sesuai dengan Permenaker RI No.04/ MEN/1980 pasal 8 yang menjelaskan APAR yang terpasang dengan bagian paling atas (puncaknya) berada pada ketinggian 1,2 meter dari permukaan lantai. Beberapa APAR yang diletakkan dengan ketinggian 1,2 meter telah sesuai dengan peraturan tersebut dan masih banyak APAR atau kelompok APAR yang diletakkan melebihi ketentuan yang dijelaskan pada peraturan tersebut.

Pada varian tinggi pemasangan APAR yang terakhir, kelompok APAR pada area laboratorium diletakkan pada sebuah keranjang yang ditempatkan di lantai. Pada keranjang tersebut tersedia dua jenis APAR yaitu APAR jenis DCP dan APAR jenis $\mathrm{CO}_{2}$. Tinggi antara dasar kelompok APAR tersebut dengan permukaan lantai adalah $25 \mathrm{~cm}$. Peletakan dua jenis APAR tersebut tidak menyalahi ketentuan karena pada Permenaker RI No.04/MEN/1980 pasal 8 juga dijelaskan bahwa APAR jenis $\mathrm{CO}_{2}$ dan tepung kering dapat ditempatkan lebih rendah dengan syarat jarak antara dasar APAR tidak kurang dari $15 \mathrm{~cm}$ dari permukaan lantai.

\section{Tinggi Pemberian Tanda APAR}

Berdasarkan hasil observasi, pemberian tanda APAR di PT. Pertamina Lubricants Production Unit Gresik terdiri dari 2 varian ketinggian. Pada varian pertama, pemberian tanda APAR dipasang dengan ketinggian 125 hingga $135 \mathrm{~cm}$ dari dasar permukaan lantai tepat di atas APAR yang bersangkutan. Pada varian kedua, pemberian tanda APAR pada area laboratorium dipasang dengan ketinggian $60 \mathrm{~cm}$ dari dasar permukaan lantai tepat di atas APAR yang bersangkutan. Hal ini tidak sesuai dengan
Permenaker RI No.04/MEN/1980 pasal 4 ayat 3 yang menjelaskan bahwa tinggi pemberian tanda pemasangan APAR adalah $125 \mathrm{~cm}$ dari dasar permukaan lantai tepat di atas APAR atau kelompok APAR yang bersangkutan. Beberapa tanda APAR yang dipasang dengan ketinggian $125 \mathrm{~cm}$ dari permukaan lantai tepat di atas APAR atau kelompok APAR yang bersangkutan telah sesuai dengan peraturan tersebut, sedangkan tanda APAR yang dipasang dengan ketinggian melebihi atau kurang dari $125 \mathrm{~cm}$ dari permukaan lantai tepat di atas APAR atau kelompok APAR yang bersangkutan tidak sesuai dengan ketentuan peraturan tersebut.

Tinggi pemberian tanda APAR pada area blending dan filling lithos dipasang dengan ketinggian mencapai 2 meter dari permukaan lantai tepat di atas APAR yang bersangkutan. Hal ini dapat ditolerir karena dalam area blending dan filling lithos tersebut terdapat mesin-mesin produksi yang cukup tinggi hingga menutupi APAR yang telah terpasang, sehingga jika terjadi keadaan darurat kebakaran, pekerja dapat mengetahui posisi APAR terpasang dan segera melakukan pemadaman api.

Berdasarkan hasil observasi, terdapat APAR yang tidak diberi tanda APAR. Selain itu, kelompok APAR yang diletakkan dalam sebuah lemari seluruhnya juga tidak diberi tanda APAR oleh manajemen PT. Pertamina Lubricants Production Unit Gresik. Hal ini tidak sesuai dengan Permenaker RI No.04/MEN/1980 pasal 4 ayat 1 yang menjelaskan bahwa setiap APAR atau kelompok APAR yang terpasang harus dilengkapi dengan tanda pemasangan APAR.

\section{Kesesuaian Tanda APAR}

Berdasarkan hasil observasi, terdapat tiga jenis tanda APAR yang terpasang di dinding PT. Pertamina Lubricants Production Unit Gresik. Jenis tanda APAR yang pertama merupakan tanda APAR yang sesuai dengan ketentuan Permenaker RI No.04/ MEN/1980 yaitu tanda APAR berbentuk segitiga sama sisi terbalik berwarna dasar merah dengan ukuran sisi $35 \mathrm{~cm}$, tulisan ALAT PEMADAM API berwarna putih dengan tinggi huruf $3 \mathrm{~cm}$ dan tanda panah berwarna putih dengan tinggi $7,5 \mathrm{~cm}$.

Jenis tanda APAR yang kedua merupakan jenis tanda APAR yang kurang sesuai dengan ketentuan peraturan karena tanda APAR tersebut terlalu kecil. Tanda APAR yang terlalu kecil akan susah terlihat oleh pekerja dari kejauhan yang akan melakukan tindakan pemadaman api jika terjadi suatu kebakaran. Jenis tanda APAR yang ketiga 
merupakan tanda APAR yang sangat tidak sesuai dengan ketentuan peraturan karena tanda APAR berbentuk persegi.

\section{Pemeliharaan APAR}

Hasil wawancara dengan petugas HSE lapangan menunjukkan bahwa telah melakukan inspeksi/ pemeriksaan pada setiap APAR yang terpasang di PT. Pertamina Lubricants Production Unit Gresik. Pemeriksaan APAR tersebut telah dilakukan secara berkala setiap satu bulan sekali. Setiap terdapat APAR yang memiliki kecacatan atau dalam keadaan rusak, maka petugas HSE Lapangan segera melakukan perbaikan atau mengganti dengan APAR baru yang tidak cacat/rusak. Hal ini telah sesuai dengan ketentuan Permenaker RI No.04/MEN/1980 pasal 11 yang menjelaskan bahwa pemeriksaan APAR dilaksanakan sebanyak dua kali dalam setahun yaitu pemeriksaan dalam jangka 6 bulan dan pemeriksaan dalam jangka 12 bulan dan bila cacat pada perlengkapan APAR maka harus segera diperbaiki atau segera diganti dengan APAR yang tidak cacat.

Berdasarkan hasil wawancara, pemeriksaan APAR yang dilakukan oleh petugas HSE Lapangan sejauh ini hanya pemeriksaan kondisi umum APAR secara visual. Pemeriksaan tersebut meliputi pemeriksaan tekanan APAR, pemeriksaan pada segel pengaman (lock pin), pemeriksaan pada corong penyemprot (nozzle), pemeriksaan pada selang (hose), pemeriksaan pada katup (valve), pemeriksaan kondisi tabung (cylinder) dan pemeriksaan terkait kebersihan APAR. Hal ini tidak sesuai dengan ketentuan yang dipersyaratkan pada Permenaker RI No.04/MEN/1980 yang menjelaskan bahwa pemeriksaan dilakukan spesifik sesuai dengan jenis APAR, melakukan penimbangan terhadap APAR yang bersangkutan, dilakukan percobaan tekan terhadap APAR yang bersangkutan, dilakukan pemeriksaan terhadap isi dari tabung APAR yang bersangkutan dan dilakukan pengisian ulang terhadap APAR yang bersangkutan.

\section{SIMPULAN}

PT. Pertamina Lubricants Production Unit Gresik sudah melakukan pemasangan dan pemeliharaan alat pemadam api ringan namun masih ada beberapa yang belum sesuai dengan peraturan. Pada variabel jenis dan kondisi pemasangan APAR, jarak pemasangan APAR dan kesesuaian tanda APAR telah sesuai dengan ketentuan Permenaker RI No.04/
MEN/1980. Variabel tinggi pemasangan APAR dan tinggi pemasangan tanda APAR masih banyak APAR dan tanda APAR yang terpasang tidak sesuai dengan ketentuan peraturan. Pemeliharaan APAR telah dilaksanakan berkala setiap satu bulan sekali oleh petugas HSE Lapangan. Pemeriksaan APAR tersebut hanya sebatas pemeriksaan kondisi umum APAR secara visual. Hal ini kurang sesuai dengan ketentuan Permenaker RI No.04/MEN/1980.

\section{DAFTAR PUSTAKA}

Angela,T.A., 2006. Studi Kasus: Evaluasi Sistem Penanggulangan Kebakaran PT. Indogravure. Kesmas: National Public Health Journal, [e-journal] 1(2): pp. 63-68

Direktorat Jenderal Minyak dan Gas Bumi RI., 2015. Lifting Pertama Produksi Minyak Banyu Urip. [online] Jakarta: Direktorat Jenderal Minyak dan Gas Bumi RI

Direktorat Jenderal Minyak dan Gas Bumi RI., 2016. Laporan Kinerja Direktorat Jenderal Minyak dan Gas Bumi. [online] Jakarta: Direktorat Jenderal Minyak dan Gas Bumi RI

Frank B., \& George G., 1985. Practical Loss Control Leadership. Georgia: International Loss Control Institute

Hambyah, R. F., 2017. Evaluasi Pemasangan APAR dalam Sistem Tanggap Darurat Kebakaran di Gedung Bedah RSUD Dr. Soetomo Surabaya. The Indonesian Journal of Occupational Safety and Health, [e-Jurnal] 5(1): pp. 41-50

ILO., 2013. Keselamatan dan Kesehatan Kerja di Tempat Kerja. Jakarta: International Labour Office

Keputusan Menteri Tenaga Kerja No. 186 Tahun 1999 tentang Penanggulangan Kebakaran di Tempat Kerja. Jakarta: Departemen Tenaga Kerja

Maruli, T., 2012. Analisis Akar Penyebab Kecelakaan Kebakaran pada Industri Minyak dan Gas Bumi dengan Menggunakan Metode Taproot di Indonesia Tahun 2006-2010. Skripsi. Depok: Fakultas Kesehatan Masyarakat Universitas Indonesia

Notoatmodjo, S., 2012. Metodologi Penelitian Kesehatan. Jakarta: Rhineka Cipta

Peraturan Menteri Tenaga Kerja No. 4 Tahun 1980 tentang Syarat-Syarat Pemasangan dan Pemeliharaan APAR. Jakarta: Departemen Tenaga Kerja

Pertamina., 2014. Data K3LL PUG Tahun 2014. Gresik: Pertamina Lubricants Production Unit Gresik 
Pertamina Lubricants., 2015. Unit Produksi Pertamina Lubricants. Jakarta: Pertamina

Polisi Resort Metro Tangerang., 2015. Kebakaran Pabrik Pengolahan Oli Bekas Satu Korban Kritis. Tangerang: Polres Metro Tangerang

Puslabfor Mabes POLRI., 2006. Data Persebaran Kejadian Kebakaran Tahun 2001-2005. Jakarta: Mabes Polri

Suma'mur., 1989. Keselamatan Kerja dan Pencegahan Kecelakaan. Jakarta: CV Haji Masagung
Undang-Undang No. 1 Tahun 1970 tentang Keselamatan Kerja. Jakarta: Departemen Tenaga Kerja

Undang-Undang No. 22 Tahun 2001 tentang Minyak dan Gas. Jakarta: Departemen Badan Usaha Milik Negara

Yervi, H., 2013. Evaluasi Penerapan Sistem Keselamatan Kebakaran pada Bangunan Gedung RS. Dr. M. Djamil Padang. Jurnal Rekayasa Sipil, [e-Jurnal] 5(2): pp. 65-76 